\title{
Use of Models of Finite Elements in the Biomechanics of the Lumbar Spine
}

\section{Uso de modelos de elementos finitos na biomecânica da coluna lombar}

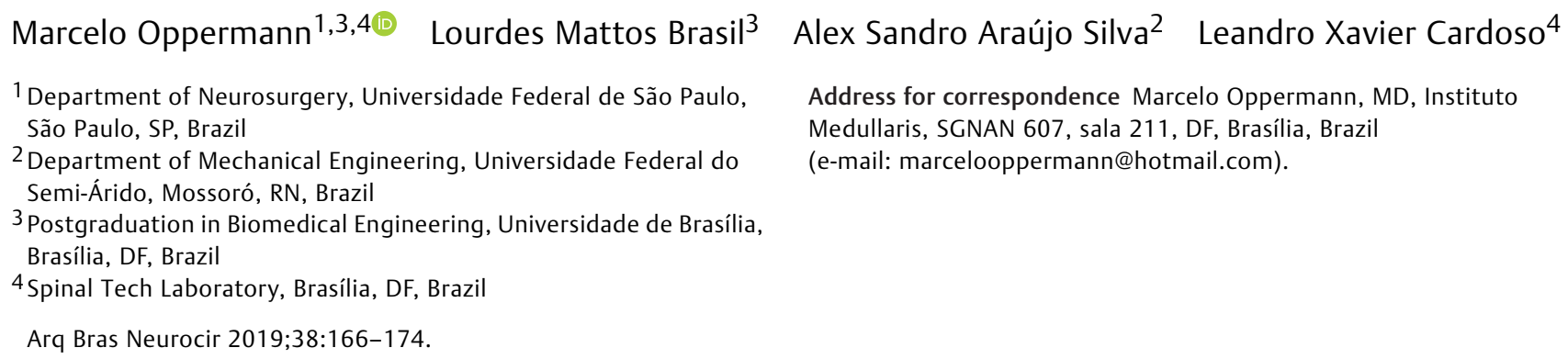
Abstract
Keywords
- spine
- finite elements
- biomechanics
- pedicle screw

\section{Resumo}
Palavras-chave
- medula
- elementos finitos
- biomecânica
- parafuso pedicular

The same correspondence between general mechanics and civil engineering is true for biomechanics and surgical implants. Currently, numerous mechanical processes are required until a prosthesis is offered to its target audience. These processes typically require human or animal vertebrae, as well as all the complexity involving such tissues, for example, an ethics committee, the availability of materials, etc. Thus, finite element models (FEMs) have become a great option to carry out biomechanical tests independently from anatomical specimens, and, at the same time, to obtain mathematical data to assist in the general physical understanding. The present review discusses the mechanical principles involved in bioengineering, clarifies the steps for the development of FEMs, and shows application scenarios for these models. To the knowledge of the authors, the present paper is the first review study in Portuguese aimed to health care professionals in a language accessible to them.

A mesma relação de correspondência que existe entre mecânica geral e construção civil ocorre entre biomecânica e implantes cirúrgicos. Atualmente, existem inúmeros processos mecânicos que são necessários até que uma prótese seja oferecida ao público alvo. Estes processos, normalmente, exigem a presença de vértebras humanas, ou mesmo de animais, e têm toda a complexidade que envolve o uso destes tecidos, como comissão de ética, disponibilidade de material, etc. Desta forma, os modelos de elementos finitos (MEFs) passaram a ser uma ótima opção, como meio de realizar testes biomecânicos e de obter independência de peças anatômicas e, ao mesmo tempo, de obter dados matemáticos que auxiliarão no entendimento geral físico. A presente revisão discute os princípios mecânicos que envolvem a bioengenharia; ademais, clarifica os passos para o desenvolvimento dos MEFs, e finaliza mostrando cenários de aplicação destes modelos. Ao conhecimento dos autores, este artigo é o primeiro estudo de revisão em português voltado para profissionais da saúde, com uma linguagem acessível para o meio médico.

(1D) Marcelo Oppermann's ORCID is https://orcid.org/0000-0003-37736284.

received

June 14, 2016

accepted

September 12, 2016
DOI https://doi.org/

$10.1055 / \mathrm{s}-0036-1594302$. ISSN $0103-5355$.
Copyright (e) 2019 by Thieme Revinter

Publicações Ltda, Rio de Janeiro, Brazil
License terms

(c) $(1) \$$ 


\section{Introduction}

In any study involving spinal biomechanics, the researcher can choose between two methods: (1) an experimental study, using vertebrae or bone structure-simulating synthetic materials and applying any mechanical factor directly or through an implant of interest; or (2) an analytical study (mathematical model), transforming study units into virtual models, and using them in virtual physical tests (finite element models [FEMs]). It is worth noting that one form does not exclude the other, and that experimental studies are indeed used in many biomechanical papers. ${ }^{1}$

The mathematical model is considered a substitute experiment that can be repeated as many times as necessary only by varying one or more parameters, resulting in different outcomes at each change. In addition, compared to experimental studies, it estimates parameters that cannot be easily measured, such as the internal stress of an object. ${ }^{2}$

Numerous purposes can be created for the biomechanical study of the spine, and some investigate the interactions between spinal parts (the relationship of the biomechanical variations of the intervertebral disc with ligaments or articular facets, for instance). ${ }^{3,4}$ It is possible to evaluate in pathological processes, such as in curvature dysfunctions, osteoporosis, etc. ${ }^{5,6}$ In addition, more recently, FEMs have served as an initial research tool for new surgical or instrumental spinal techniques. ${ }^{7}$

In the present review, the authors aim to provide specialized health care professionals with the knowledge of terms used in vertebral biomechanics and the principle behind finite elements (FEs), in addition to presenting studies about mathematical mechanical tests for implant simulations.

\section{Methods}

The methodology used in the present review focused on papers and books about spinal biomechanical tests using FEMs, without specifying the date of publication. The tools used were PubMed, as a way of retrieving scientific papers, and HOLLIS + (a research tool from Harvard University) to search for textbooks. In both, the following terms were inserted: finite element models, spine biomechanics, and biomechanical tests. We have selected papers and books that were relevant to the present review, and presented data to achieve the proposed objectives

\section{Biomechanics}

To better understand the FEM principle, the researcher needs to know some general concepts of material mechanics, such as elastic modulus (E), stress $(\sigma)$, strain $(\varepsilon)$, and von Mises stress, as well as other terms, such as elastic and plastic deformation, and variations in material tropism.

\section{Stress/Strain}

One needs to understand how a material will deform according to a specific load imposed on it. This knowledge is required to prevent failure in any organic or inorganic compound. This behavior will depend on the dimensions of the study material (area and length), as well as on the load to which it is exposed. - Fig. 1 shows that the strain variation ( $\delta$ or D) - or, in other words, the final strain $(L)$ minus the initial strain (Lo) - is directly proportional to the area increase and inversely proportional to the length increase.

However, this proportional behavior is linear only until the beginning of the intermolecular failure process; from this point on, the direct (linear) correlation will no longer be the same, and the strain may triple or quadruple at each unit increase in the load (-Fig. 2).

Stress $(\sigma)$ will depend on the load $(P)$ exerted on a certain area $(\mathrm{A})$, according to equation 1 :

$$
\sigma=(\mathrm{EQ} 1)
$$

The term stress, not load, should be applied, since it configures the amount of weight applied per unit area in greater detail.

The deformity that the object undergoes under stress depends on the strain variation $(\delta)$ and on the initial length, according to equation 2 .

$$
\varepsilon=(\mathrm{EQ} 2)
$$

When stress $(\sigma)$ is plotted against strain $(\varepsilon)$, it is possible to identify a characteristic curve for each material, regardless of the dimensions of the studied part. This curve is called a stress-strain diagram (-Fig. 3). This graph varies a lot from one structure to another and within the same material, depending on the temperature of the specimen and on the load rate applied.

As the sample is subjected to an increasing load, its length increases linearly. Thus, the initial portion of the diagram is a straight line that ascends steeply. However, after reaching a critical stress value ( $\sigma \gamma$ ), also known as yield stress, the deformation process starts, and a smaller load is required to achieve the same deformation. After reaching a maximum stress value, the sample fails (green line in - Fig. 3 ).

It is worth mentioning that, during the linear phase, if the applied stress is completely withdrawn, the length of the material returns to baseline, without any resulting deformity (elastic phase). However, after the yield stress point, the object remains deformed even if no stress is present (plastic phase), in a process called plastic deformation.

This behavior distinguishes two types of materials: malleable and rigid materials. The former resembles the one previously described, with distinct phases; the rigid ones do not present a plastic phase, since they go from an elastic phase directly to failure. The first group is represented by steel and iron; the second one, by glass and ceramics (-Fig. 4).

\section{Elastic Modulus}

Most materials used in real practice are developed to withstand relative strain, that is, variations only in the linear area of the stress-strain diagram, in which stress $(\sigma)$ is directly proportional to strain $(\varepsilon)$. The graphical slope of this relationship is described by the elastic modulus or Young modulus $(E)$. It is a mechanical parameter that measures 


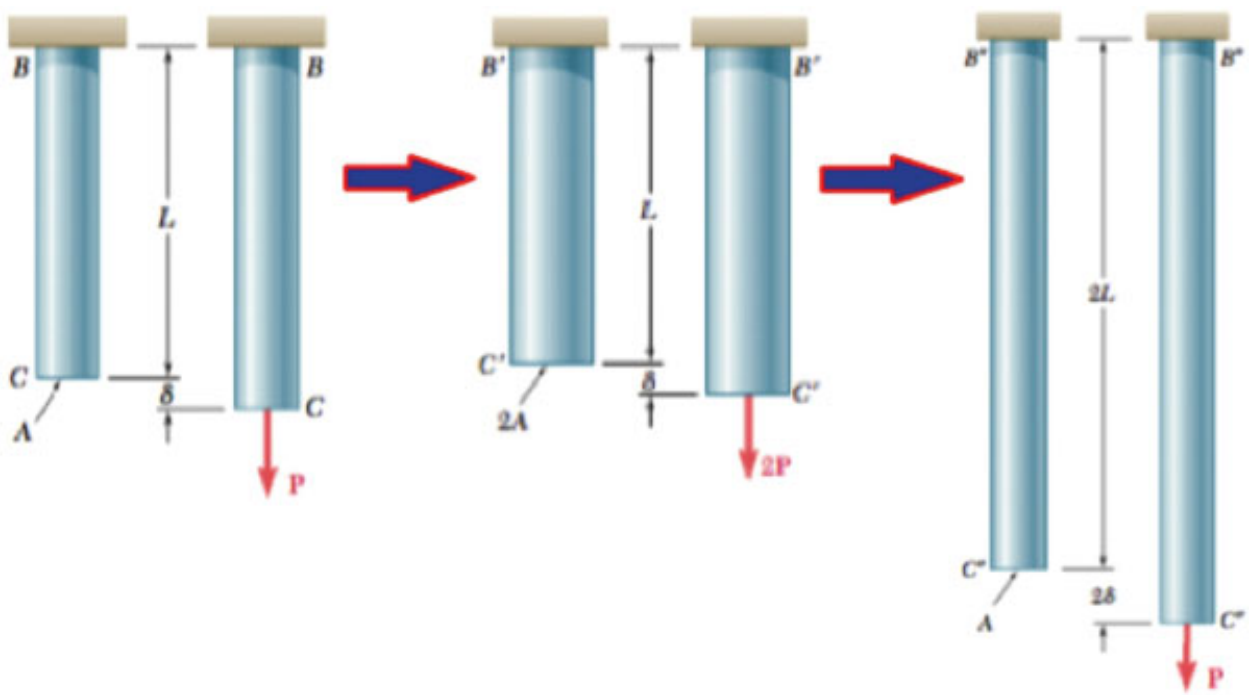

Fig. 1 A bar $(B C)$ of size $L$ and area $A$ suffers a load $P$ in the direction opposite to its fixation, thus exhibiting a variation of size $D$. However, as shown in the second figure, increasing the area to $2 \mathrm{~A}$, in order to achieve the same size variation $\mathrm{D}$, the load exerted should be $2 \mathrm{P}$. In the last example, a bar of size $2 \mathrm{~L}$ with the same load $\mathrm{P}$ will suffer a variation of $2 \times \mathrm{D}$.

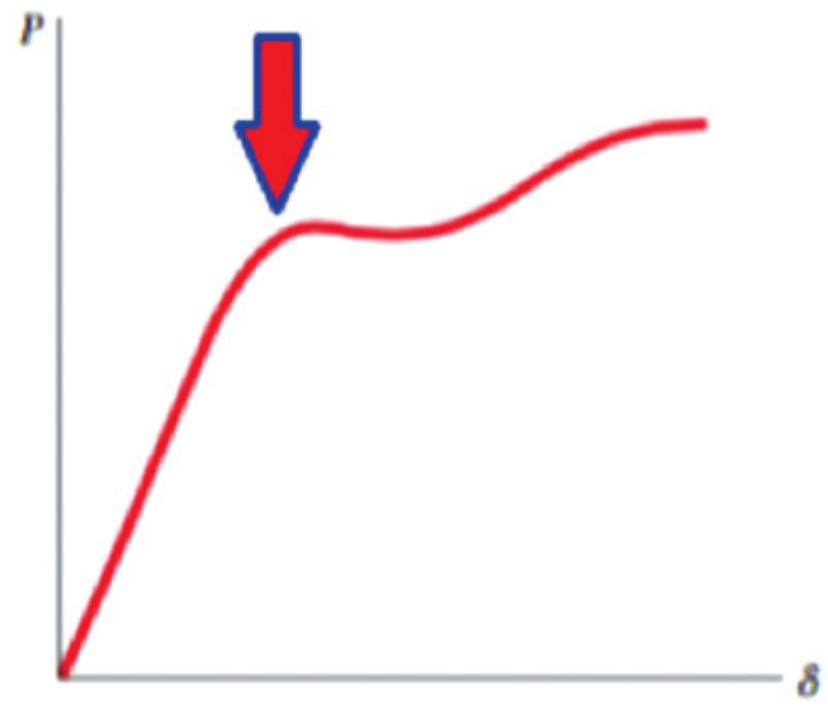

Fig. 2 Image showing that a load $(P)$ increase is directly related to a strain $(\delta)$ increase up to the point (indicated by the arrow) in which the object distends differently to a unitary load increase.

the rigidity of a solid material, and it originates from the energy binding the atoms of the material. This modulus roughly divides materials in two major classes: flexible and rigid materials. A material with a high Young modulus is rigid; ${ }^{8}$ therefore, if a material has a steeper slope, it is said to be rigid; otherwise, it is described as malleable.

\section{Von Mises Stress}

Von Mises stress is a mechanical parameter widely used to determine if the design will withstand a certain loading condition. ${ }^{9}$ With this information, an engineer can tell whether the design will fail.

It represents the maximum load that the structure will withstand before going into the plastic phase, through a strain ratio up to the yield stress. ${ }^{10}$ In mathematical FE

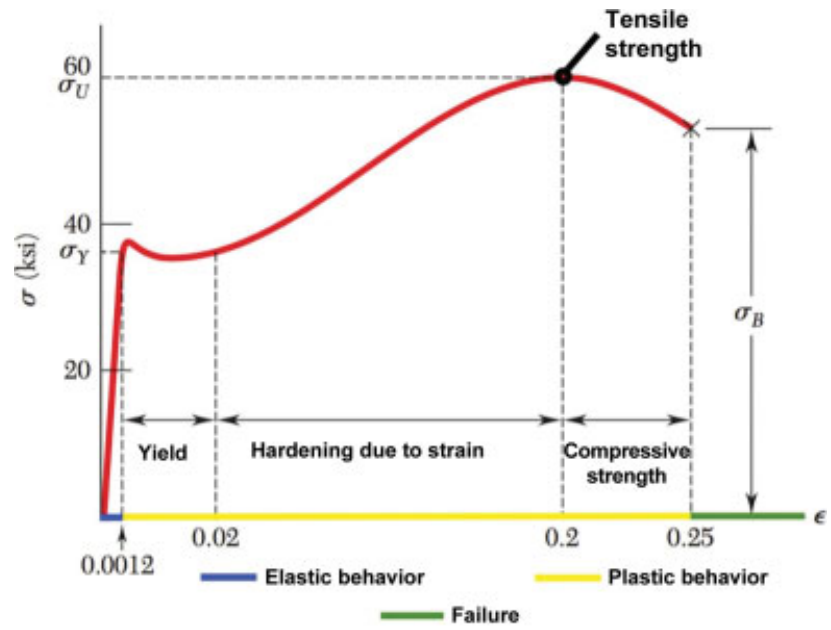

Fig. 3 Stress-strain diagram of a given material $(\sigma=$ stress measured in ksi - pound force per square inch) showing its yield $(\mathrm{Y})$, maximum $(\mathrm{U})$, and failure (B) points. The elastic or linear behavior and the plastic behavior can also be seen. Source: personal archive.

models, it is said that when an object deforms $>3 \%$ of its initial size, it will exit the elastic phase, and any additional load will deform it in a definitive way.

\section{Poisson Coefficient}

A tensile stress exerted on a piece of any material results in longitudinal deformation, proportional to the applied force, and determined by its elastic or Young modulus.

The Young modulus is defined only by longitudinal deformation; however, any "stretched" elastic material also undergoes a transverse deformation, which is proportional to the longitudinal strain applied. These two strain types can be seen by stretching a piece of rubber with enough malleability. ${ }^{11}$

The ratio of transverse to longitudinal strain in the direction of the tensile stress is called the Poisson coefficient (or ratio) (v). ${ }^{11}$ 


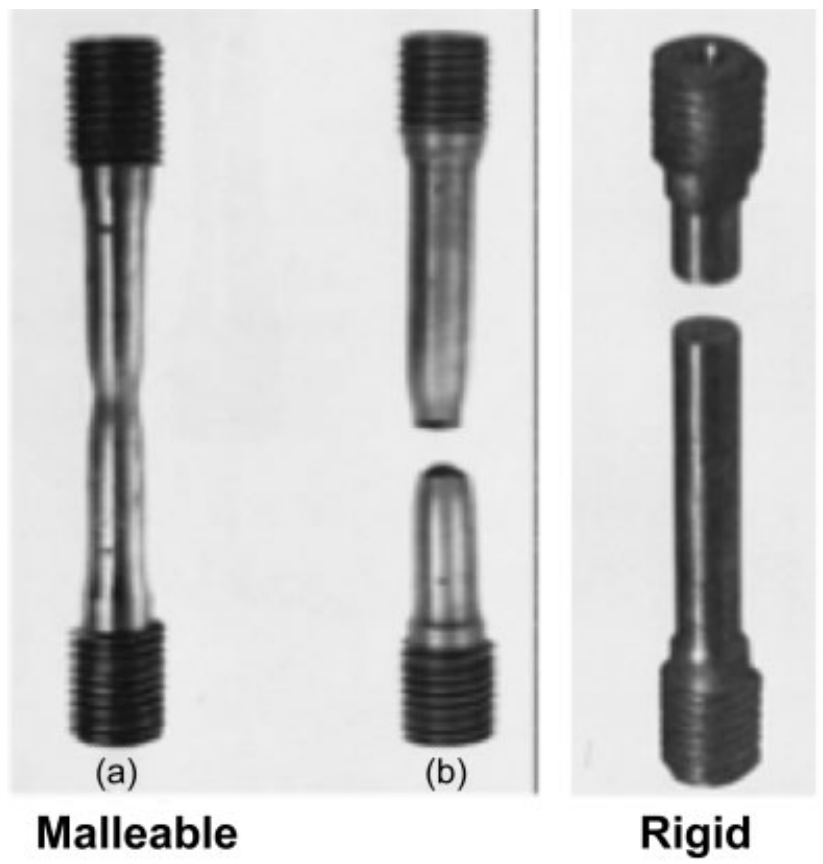

Fig. 4 Behavior of samples of materials: rigid (glass) and malleable (steel). Note the existing deformation in one material and its absence in the other. Source: personal archive.

\section{Isotropic and Anisotropic Materials}

In isotropic materials, their physical characteristics - including elastic modulus and von Mises stress - are the same in every loading direction. In anisotropic materials, these physical parameters vary depending on the position in which tension is exerted. The vertebral bone is an anisotropic material, since its trabecular and cortical orientations are not the same in the laterolateral, anteroposterior, or craniocaudal directions. ${ }^{11}$

\section{Finite Elements}

Nowadays, digital tools such as FEs or FEMs are widespread in analytical engineering, as well as in medicine. ${ }^{12}$ These tools are extensively used to analyze solid materials, structures, heat transfers, and so on. ${ }^{13}$ At the spine, Brekelmans et al $^{14}$ were the first to use mathematical models to represent bone tissue. Later, several studies regarding the spine were performed. ${ }^{15}$

Finite element models were created to aid the understanding of certain physical-mechanical structural behaviors, due to variations in weight, stress, or even in the dimensions of these structures. It was soon recognized that their use could avoid unnecessary expenditures with actual mechanical tests.

It is important to understand that FEMs deal with physical problems, and, to that end, mathematical equations must be created to simulate problems and solutions. It is worth mentioning that FEMs will only answer questions with the information inserted in the software, and that they will never be able to solve more than what is contained in this database. ${ }^{13,16}$

Many studies use FEMs to analyze normal vertebrae under various stress situations, including flexion, extension, and going from a sitting to a standing position. ${ }^{17}$ Some focus their attention on models in which a pre-existing pathology requires surgical correction or the implantation of metallic prostheses. Finite element models have been recently more explored in these cases. ${ }^{6,18-22}$

Both in engineering and in biomechanics, the construction and processing of FEMs begin with the identification of the studied object; next, constraints and stresses are imputed to the model, resulting in postprocessing.

In physiological studies, the models created contemplate the entire structure of the functional vertebral unit, that is, models from two ${ }^{16,23-25}$ or more articular levels are based on images obtained through computed tomography (CT) scans or magnetic resonance imaging (MRI) (e.g., stereolithography [STL] - a 3D format). ${ }^{3}$ These models can represent the vertebra, the intervertebral disc, the articular facets, and all of the ligaments with their own meshes. ${ }^{26}$

In pathological models, the studied material may have several shapes (square, cylindrical) to simplify the model. Thus, in the first case, the appearance of the testing model will be very similar to the spine. ${ }^{3}$ In the second case, it will depend on the format stipulated by the researcher (-Fig. 5). . $^{18,27}$

After the creation of the models, or meshes, as described in mechanical language, physical rules are stipulated for each portion. For instance, one part may be fixed, and another movable in one or more directions. In addition, it is possible to stipulate at which point a load will be inserted, if any. Moreover, each structure needs to be classified as isotropic or anisotropic, more or less rigid (elastic modulus), and its behavior (plastic and/or elastic phase), as well as when such behavior(s) will begin (von Mises stress) must be determined.

Kurutz et $\mathrm{al}^{4}$ reviewed the values imposed on vertebral structures and demonstrated their enormous variability. For example, some authors have stipulated an elastic modulus of 5,000 Mpa for the cortical bone, and of $50 \mathrm{MPa}$ for the trabecular bone; ${ }^{17}$ however, for other researchers, these values are 22,000 $\mathrm{MPa}$ and $10 \mathrm{MPa}$, respectively. ${ }^{28}$ This means that there is not a standard form to mathematically define each structure. This difficulty results from two
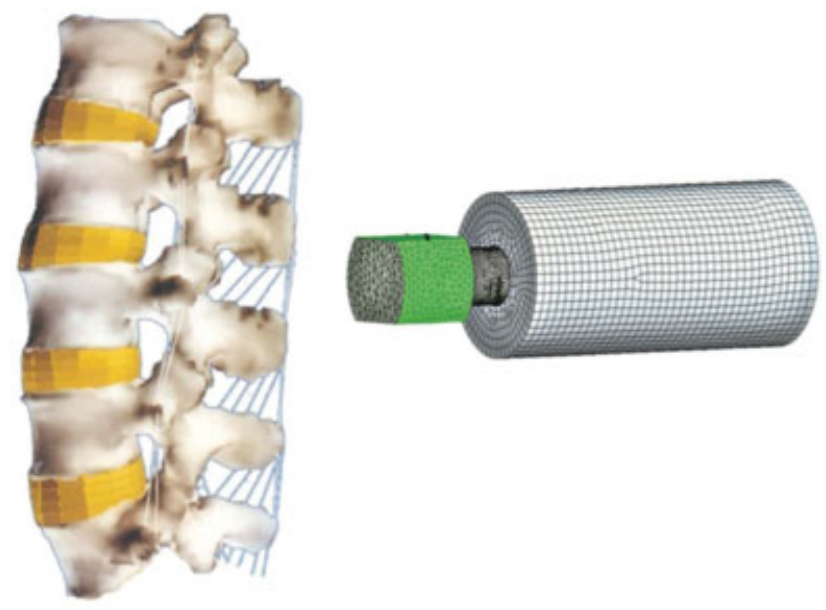

Fig. 5 Different ways of drawing the object under study that will be the basis for the FEM. Source: adapted from Amaritsakul et al ${ }^{18}$ and Dreischarf et al. ${ }^{3}$ (with permission from GB publisher 4946272 12). 
aspects: (1) the choice of the method used to measure the physical characteristics of the two bone types; ${ }^{29}$ and (2) the disparity between the characteristics of the samples that significatively influence the results. ${ }^{30}$

Lastly, there are the results from the so-called postprocessing phase. This occurs primarily in two forms: the stress in a certain structure and its strain, both under the effect of a load or of a movement. That is, whenever a model is created and situations are stipulated, some structural data are sought under these two variables. In a physiological model, stress and displacement are seen in one vertebra over another, in a ligament, or even in an intervertebral disc. ${ }^{3}$ In a pathological model with implants, it is evaluated whether it will carry the proposed load, or how much movement there will be within the supposed bone tissue. ${ }^{12,18-20,27}$

In summary, FEMs serve a range of contexts and greatly facilitate the understanding of how each structure will behave in a given situation. In addition, they do not need physical structures and complex machinery, since they are based on mathematical models. And, lastly, they do not require the difficult and time-consuming approval by ethics committee groups.

\section{Applications}

Lately, spinal FEMs have been used for a better understanding of the mechanics of vertebral implants. However, in the past, when this tool began to be used in the spine, most studies proposed a better understanding of the functionality and of the absorption of loads that are inherent to the body. In the present review, the focus is on studies meaningful for these applications.

\section{Finite Element Models in Implants}

Amaritsakul et al, in order to analyze pedicle screws failures, such as breaking, loosening or bending, studied five types of screws in an FE study. ${ }^{18}$ Their work aimed to evaluate which screw would have the best fixation and the lower failure rate. An FEM was created in a 3D cylindrical mould, simulating the bone space in which the screw would be inserted. The screw mesh had 10-node tetrahedral elements; the bone (cylinder) had a mesh of 20-node tetrahedral elements, both at a distance of $1.2 \mathrm{~mm}$. The contact surface between the two elements (bone and screw) was stipulated as frictionless; furthermore, axial rotational movement was not allowed.

To evaluate its capacity, the screw was folded into a $20 \mathrm{~mm}$ diameter cylinder, with an elastic modulus $(E)$ of $20 \mathrm{GPa}$, and with a Poisson coefficient (v) of 0.3. A $225 \mathrm{~N}$ load was applied transversely to the screw (-Fig. 6a). The result was measured by the maximum stress at the screw surface, representing the resistance to bending.

To simulate the pullout, the cylinder diameter was increased to $30 \mathrm{~mm}$, and $E$ was decreased to $137.5 \mathrm{MPa}$ $(\mathrm{v}=0.3)$ to mimic an osteoporotic bone (-Fig. 6b). In addition, it was predicted that, at the insertion of the screw, the bone would be compacted (bone debris) around it. This process was carried out from the mathematical point of view through an adjustment in the elastic modulus, with a function of the change of the density squared, as described by other authors. ${ }^{31}$ As a traction simulator, a displacement of $0.01 \mathrm{~mm}$ was applied to the screw, and the structures around it were set so as to not allow any movement.

In the paper, the authors discuss the results of each screw, concluding that the FEs were adequate to obtain mechanical responses; in addition, they could generate multiple response parameters (bending and pullout) in the same model by data interpolation.

Macedo et al tried to validate a virtual model for the study of double-threaded and cylindrical screws in order to evaluate how much the geometry would influence their mechanical behavior and anchoring, as well as to determine which one would have the best long-term performance. ${ }^{20}$ All of the components were considered homogeneous and isotropic. The simulation used a polyurethane block (representing the bone) with an E of $0.023 \mathrm{GPa}$ and a v of 0.30 , and a screw with an $\mathrm{E}$ of $114 \mathrm{GPa}$ and a $\mathrm{v}$ of 0.30 , as previously described by other researchers. ${ }^{31} \mathrm{~A}$ force of $50 \mathrm{~N}$ in the (pulling) direction,

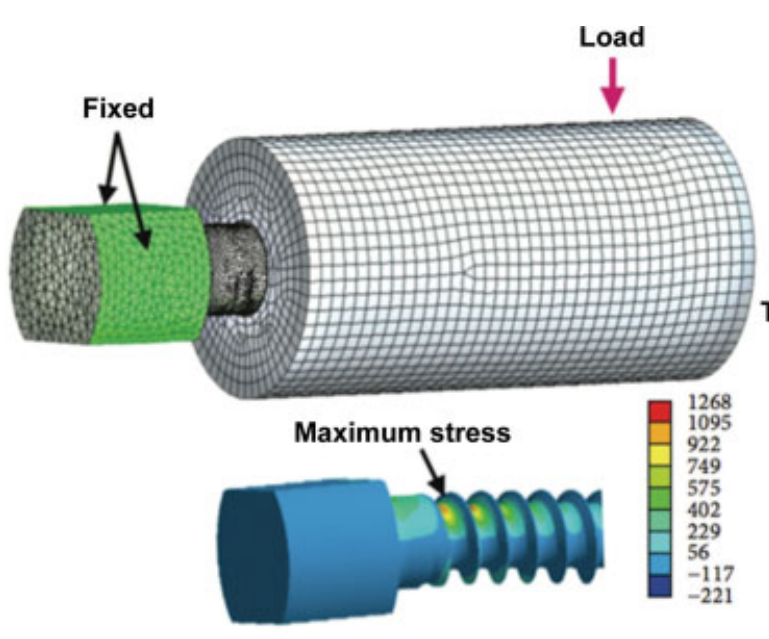

(a)

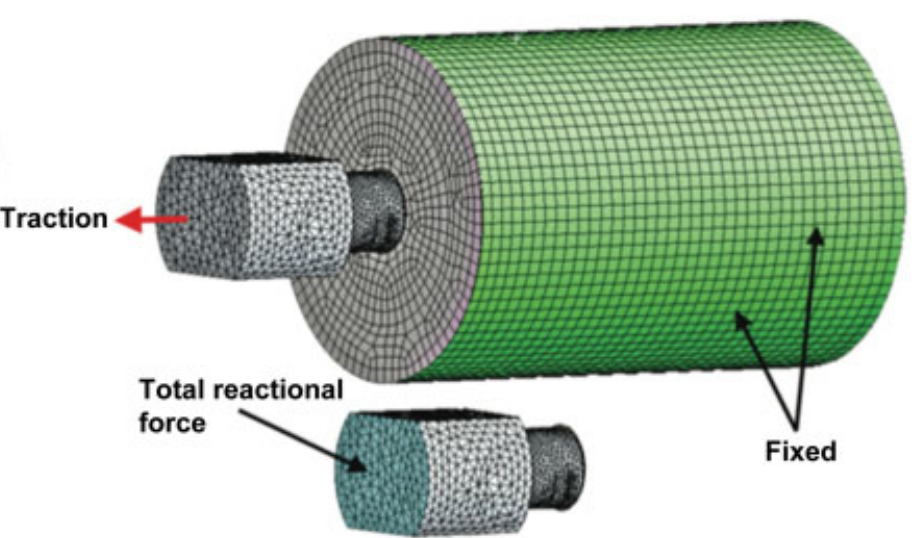

(b)

Fig. 6 Screw FEM; (a) bending and (b) pullout. The cylinders represent the bone with the rigid and movable (stressed) regions. Source: adapted from Amaritsakul et al. ${ }^{18}$ 

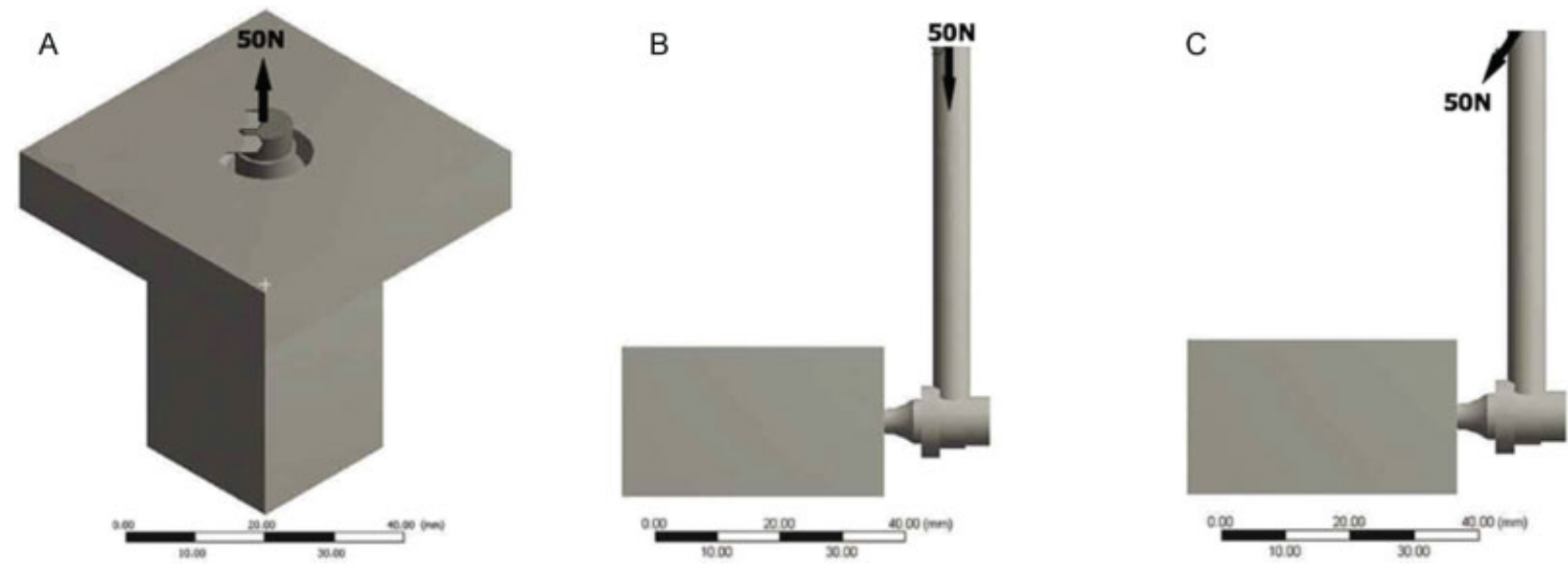

Fig. 7 Loading simulation conditions $(50 \mathrm{~N})$ on the screw: A, along; B, transversely; and C, obliquely $\left(45^{\circ}\right)$.

transversely and obliquely to the screw, was created (-Fig. 7). The von Mises stress distribution was evaluated in the vicinity of the screw at 13 points, $6 \mathrm{~mm}$ apart. The stresses generated along the internal diameter and the upper, central, and lower region of the screws were evaluated in 30 points each (-Fig. 8).

This study, simple in facts, shows the presence of other loading forms in addition to pullout, such as transverse and oblique loads. However, to perform this analysis, the bone must not be considered an isotropic material, but presenting different mechanical characteristics at different planes. As such, the FEM would be more convincing if it contemplated an anisotropic pattern, or at least, a transversely isotropic pattern. $28,32,33$

\section{Physiological Finite Element Models}

Dreischarf et al, ${ }^{34}$ assuming that in vivo tests are unable to establish the compression force $(\mathrm{CF})$ to which the interver- tebral disc (IVD) is exposed, declared, aided by other studies, $^{35,36}$ that an approximate $C F$ value can be estimated from the intradiscal pressure (IP) in the disc area (A), and that the individual correction factor for human vertebrae was defined as 0.66 . In this situation, in a person standing up, the load over the disc would be of $\sim 500 \mathrm{~N}$. However, because this correction factor is not always adequate for each individual person, the authors propose calculating the CF using FEMs. To do so, they constructed an intact model of the lumbosacral spine with all of its ligaments. As a reference for IPs, using the literature, they have established that the IVD is in a noncompression situation. Fibrous annulus fibers were described with 14 bands and a crisscross pattern. The articular facets were designed as containing a frictionless cartilaginous layer, but with a squared increase according to the decreased IVD height.

The mechanical properties of the virtual spine components were taken from the literature and are shown in - Fig. 9.

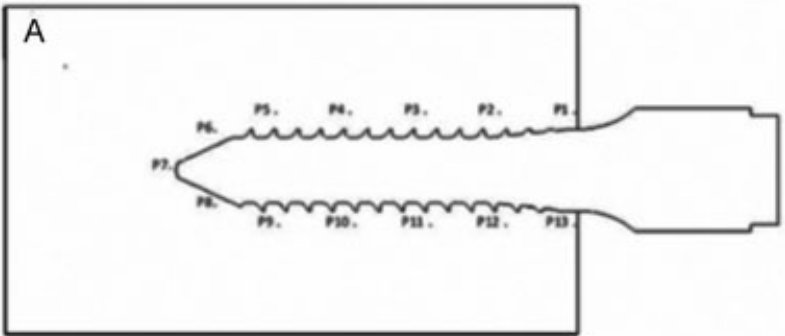

B

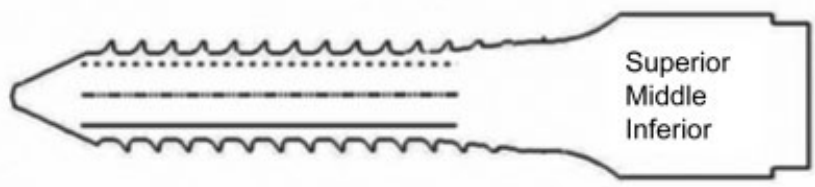

Fig. 8 Points analyzed on polyurethane foam (von Mises stress) and screw.

\begin{tabular}{lll}
\hline Component & Elastic modulus & Poisson coefficient \\
\hline Cortical bone & 10,000 & 0.30 \\
Cancellous bone & $200 / 140$ & $0.45 / 0.315$ \\
Posterior bone elements & 3,500 & 0.25 \\
Fibrous annulus ground substance & Hyperelastic, neo Hookean C10=0.3448, D1=0.3 & - \\
Fibrous annulus fibers & Nonlinear and depending on the distance from the center of the disk & - \\
Ligaments & Nonlinear & - \\
Articular facet cartilage & Smooth contact & - \\
\hline
\end{tabular}

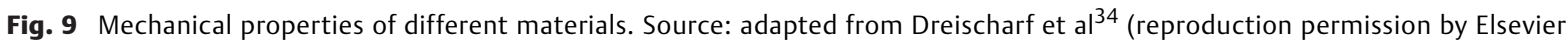
3940280612680). 
172 Use of Models of Finite Elements in the Biomechanics of the Lumbar Spine Oppermann et al.

\begin{tabular}{lcl}
\hline $\begin{array}{l}\text { Body } \\
\text { position }\end{array}$ & $\begin{array}{l}\text { Continuous } \\
\text { loading }\end{array}$ & $\begin{array}{l}\text { Initial } \\
\text { momentum }\end{array}$ \\
\hline Standing up & $500 \mathrm{~N}$ & - \\
Flexion & $1,175 \mathrm{~N}$ & $7.5 \mathrm{Nm}$ \\
Extension & $500 \mathrm{~N}$ & $7.5 \mathrm{Nm}$ \\
Lateral flexion & $700 \mathrm{~N}$ & $7.8 \mathrm{Nm}$ \\
Axial rotation & $720 \mathrm{~N}$ & $5.5 \mathrm{Nm}$ \\
\hline
\end{tabular}

Fig. 10 Loading values for simulations in different body positions. Source: adapted from Dreischarf et al. ${ }^{34}$

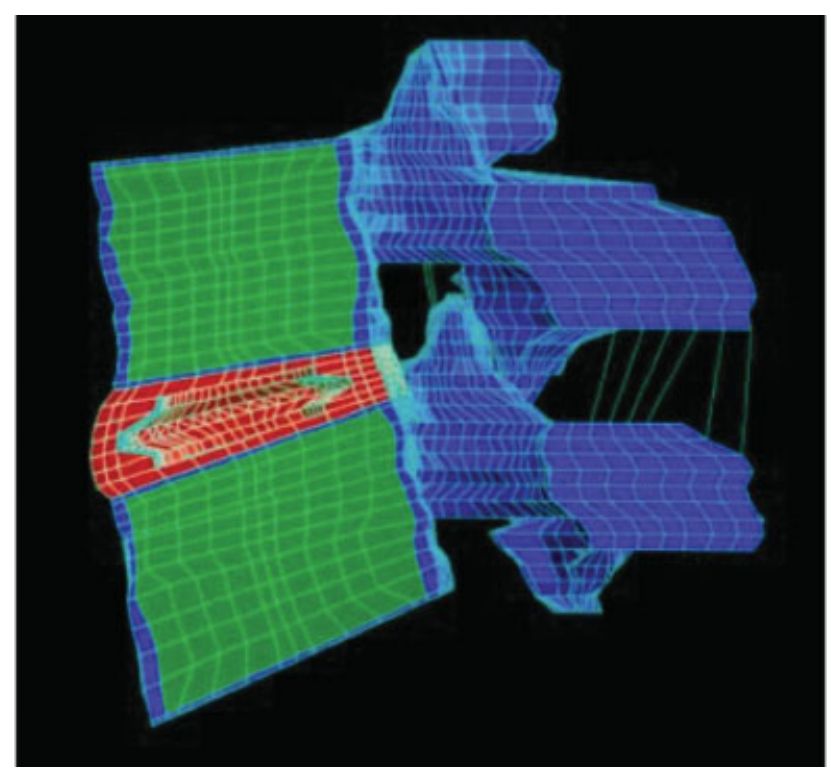

Fig. 11 Image of the three-dimensional mesh of the $4^{\text {th }}$ and $5^{\text {th }}$ lumbar vertebrae. Source: adapted from Goto et al. ${ }^{38}$

The present study focused on the L4-L5 level to facilitate the understanding of such a complex system. The loads applied according to different positions can be seen in - Fig. 10.
The authors used several indicators to measure the $\mathrm{CF}$, but PI alone was not enough to understand the real situation of CF over IVD.

Another very representative paper is the work by Fagan et al, who reviewed the studies to date, with basic modeling concepts and stipulated values. This study confirms FEMs as an excellent method for studying spinal biomechanics, reducing the use of human vertebrae and the reliance on animal studies. ${ }^{37}$

Goto et al, using FEMs, proposed to elucidate the damage that IVD, articular facets, and endplates undergo in pathological situations. ${ }^{38}$ Meshes were prepared based on CT scan images of a 29-year-old man without any vertebral pathology between the $4^{\text {th }}$ and $5^{\text {th }}$ lumbar vertebrae (-Fig. 11).

The application of the properties was stipulated according to -Fig. 12. A nonlinear pattern was attributed to the ligaments; for the facets, frictionless spaces were created. An IVD was created with a ratio of 3:7 between the nucleus pulposus and the fibrous annulus, respectively, with an intradiscal pressure of $1.32 \mathrm{MPa}$ at the flexural and the upright posture, and of $0.6 \mathrm{MPa}$ at extension. A $294 \mathrm{~N}$ load was applied gradually, and the flexion/extension stress of 15 $\mathrm{N}-\mathrm{m}$ was inserted in 15 steps. The postprocessing intended to evaluate the von Mises stress (failure stress) in several disc areas.

The study demonstrated an increase in the von Mises stress in the posterior portion of the fibrous annulus. This stress was 1.5 times higher in flexion compared to other positions (-Fig. 13).

\section{Conclusions}

In the present review, the authors were able to introduce to health care professionals, especially to spine specialists, the basic concepts of general and vertebral biomechanics, to demystify the complexities involving finite models and to show their usefulness in anatomy/physiology studies and in the simulation of scenarios with implants.

\begin{tabular}{llcc}
\hline Material & Element type & $\begin{array}{c}\text { Young modulus } \\
(\mathbf{E}: \mathbf{M p a})\end{array}$ & $\begin{array}{c}\text { Poisson } \\
\text { coefficient (v) }\end{array}$ \\
\hline Cortical bone & 8-solid node & 12,000 & 0.3 \\
Cancellous bone & 8-solid node & 100 & 0.2 \\
Endplate & 8-solid node & 23.8 & 0.4 \\
Ground ring & $8-$ solid node & 4.2 & 0.45 \\
Intradiscal pressure & - & - & - \\
$\quad$ Flexion & - & 1.32 & - \\
Vertical & - & 0.54 & - \\
Extension & - & 0.59 & - \\
Fibrous annulus & 2-solid node & Nonlinear & - \\
Ligaments & 2-solid node & Nonlinear & Area (mm2) \\
Anterior & - & - & 75.9 \\
$\quad$ Posterior & - & - & 51.8 \\
Interspinal & - & - & 36.3 \\
Supraspinal & - & - & 75.7 \\
Intertransverse & - & - & 2 \\
Facet & Gap & - & - \\
\hline
\end{tabular}

Fig. 12 Properties and values of materials and their types. Source: adapted from Goto et al. ${ }^{38}$ 

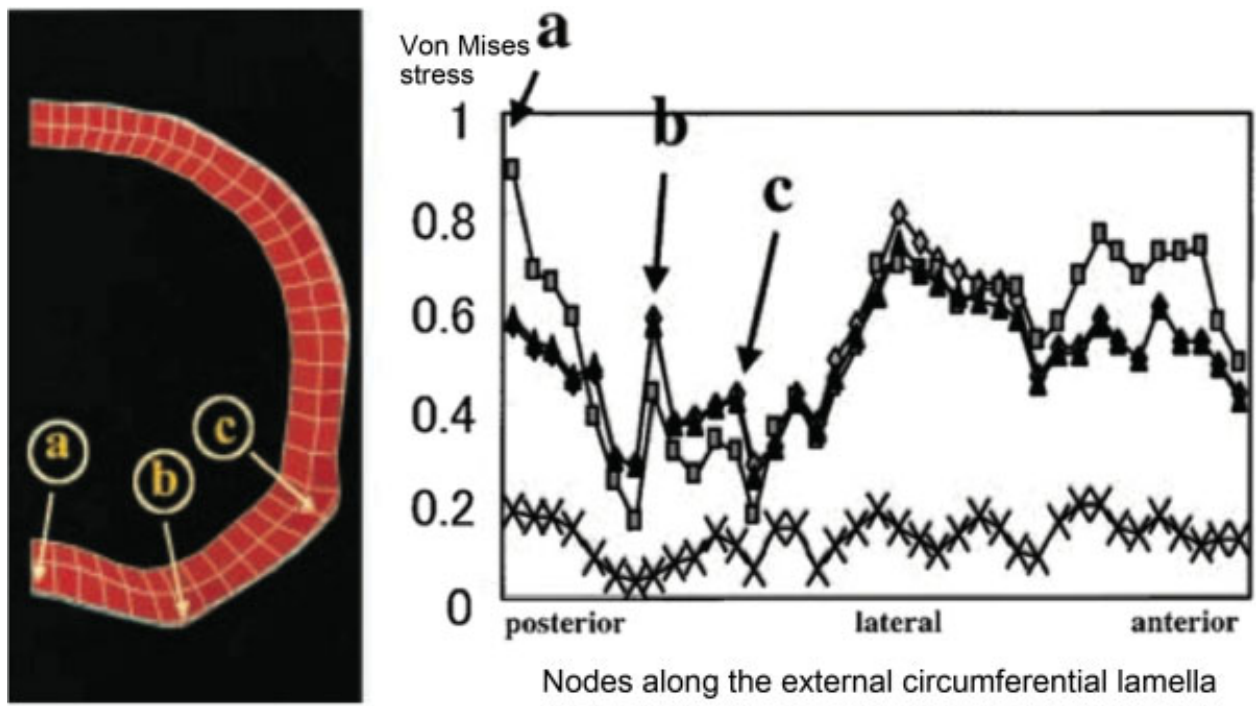

Nodes along the external circumferential lamella

Fig. 13 Von Mises stress in different structures of the disc fibrous annulus in flexed position. Source: adapted from Goto et al. ${ }^{38}$

There is a vast of literature on the subjects discussed here, but few in Portuguese. The idea is to stimulate Brazilian researchers to perform more biomechanical and FEM work involving the spine.

Conflicts of Interests

The authors have no conflicts of interests to declare.

\section{References}

1 Denozière G, Ku DN. Biomechanical comparison between fusion of two vertebrae and implantation of an artificial intervertebral disc. J Biomech 2006;39(04):766-775

2 Hutton DV. Fundamentals of Finite Element Analysis. McGrawHill Science; 2003

3 Dreischarf M, Zander T, Shirazi-Adl A, et al. Comparison of eight published static finite element models of the intact lumbar spine: predictive power of models improves when combined together. J Biomech 2014;47(08):1757-1766

4 Kurutz M. Finite Element Modelling of Human Lumbar Spine. In: Moratal D, ed. Finite Element Analysis. 1st ed. INTECH Open Access Publisher; 2010:210-236

5 Bauer JS, Sidorenko I, Mueller D, et al. Prediction of bone strength by $\mu \mathrm{CT}$ and MDCT-based finite-element-models: how much spatial resolution is needed? Eur J Radiol 2014;83(01):e36-e42

6 Zhang QH, Teo EC. Finite element application in implant research for treatment of lumbar degenerative disc disease. Med Eng Phys 2008;30(10):1246-1256

7 Teyfik D, Basgül C. The Pullout Performance of Pedicle Screws. 1st ed. New York, NY: Springer; 2015

8 Twomey L, Taylor J. Flexion creep deformation and hysteresis in the lumbar vertebral column. Spine 1982;7(02):116-122

9 Gilbertson LG, Goel VK, Kong WZ, Clausen JD. Finite element methods in spine biomechanics research. Crit Rev Biomed Eng 1995;23(5-6):411-473

10 Beer FP, Johnston ER, DeWolf JT. Mechanics of Materials. McGrawHill Higher Education; 2006

11 Rittel D, Silva ML, Poon B, Ravichandran G. Thermomechanical behavior of single crystalline tantalum in the static and dynamic regime. Mech Mater 2009;41(12):1323-1329

12 Matsukawa K, Yato Y, Imabayashi H, Hosogane N, Asazuma T, Chiba K. Biomechanical evaluation of lumbar pedicle screws in spondylolytic vertebrae: comparison of fixation strength between the traditional trajectory and a cortical bone trajectory. J Neurosurg Spine 2016;24(06):910-915

13 Bathe K. Finite Element Procedures. Prentice Hall; 2006. doi:. Doi: $10.2307 / 962758$

14 Brekelmans WA, Poort HW, Slooff TJ. A new method to analyse the mechanical behaviour of skeletal parts. Acta Orthop Scand 1972; 43(05):301-317

15 Yoganandan N, Myklebust JB, Ray G, Sances A Jr. Mathematical and finite element analysis of spine injuries. Crit Rev Biomed Eng 1987;15(01):29-93

16 Rohlmann A, Zander T, Schmidt H, Wilke HJH-J, Bergmann G. Analysis of the influence of disc degeneration on the mechanical behaviour of a lumbar motion segment using the finite element method. J Biomech 2006;39(13):2484-2490

17 Zander T, Rohlmann A, Bergmann G. Influence of different artificial disc kinematics on spine biomechanics. Clin Biomech (Bristol, Avon) 2009;24(02):135-142

18 Amaritsakul Y, Chao C-K, Lin J. Multiobjective optimization design of spinal pedicle screws using neural networks and genetic algorithm: mathematical models and mechanical validation. Comput Math Methods Med 2013;2013:462875

19 Chazistergos P, Ferentinos G. Investigation of the Behaviour of the Pedicle Screw-Vertebral BoneComplex,When Subjected to Pure Pull-Out Loads. 2006. http://ansys.com/staticas-sets/ANSYS/staticassets/resourcelibrary/confpaper/2006-Int-AN-SYSConf-126. pdf

20 Macedo AP, Luiz H, Defino A, Shimano AC. Biomechanical Evaluation of a Spinal Screw Fixation System by the Finite Element Method. Int J Morphol 2015;33(01):318-326

21 Hansson TH, Keller TS, Spengler DM. Mechanical behavior of the human lumbar spine. II. Fatigue strength during dynamic compressive loading. J Orthop Res 1987;5(04):479-487

22 LeeJK, Amorosa L, Cho SK, Weidenbaum M, Kim Y. Recurrent lumbar disk herniation. J Am Acad Orthop Surg 2010;18(06):327-337

23 Lee S-H, Im YJ, Kim KT, Kim YH, Park WM, Kim K. Comparison of cervical spine biomechanics after fixed-and mobile-core artificial disc replacement: a finite element analysis. Spine 2011;36(09):700-708

24 Baroud G, Nemes J, Heini P, Steffen T. Load shift of the intervertebral disc after a vertebroplasty: a finite-element study. Eur Spine J 2003;12(04):421-426

25 Graeff C, Marin F, Petto H, et al. High resolution quantitative computed tomography-based assessment of trabecular 
microstructure and strength estimates by finite-element analysis of the spine, but not DXA, reflects vertebral fracture status in men with glucocorticoid-induced osteoporosis. Bone 2013;52 (02):568-577

26 Shirazi-Adl A. Biomechanics of the lumbar spine in sagittal/lateral moments. Spine 1994;19(21):2407-2414

27 Shih KS, Hsu CC, Hou SM, Yu SC, Liaw CK. Comparison of the bending performance of solid and cannulated spinal pedicle screws using finite element analyses and biomechanical tests. Med Eng Phys 2015;37(09):879-884

28 Schmidt H, Heuer F, Wilke H-J. Which axial and bending stiffnesses of posterior implants are required to design a flexible lumbar stabilization system? J Biomech 2009;42(01):48-54

29 Huang H-L, Tsai M-T, Lin D-J, Chien C-S, Hsu J-T. A new method to evaluate the elastic modulus of cortical bone by using a combined computed tomography and finite element approach. Comput Biol Med 2010;40(04):464-468

30 Choi K, Kuhn JL, Ciarelli MJ, Goldstein SA. The elastic moduli of human subchondral, trabecular, and cortical bone tissue and the size-dependency of cortical bone modulus. J Biomech 1990;23 (11):1103-1113

31 Hsu C-C, Chao C-K, Wang J-L, Hou S-M, Tsai Y-T, Lin J. Increase of pullout strength of spinal pedicle screws with conical core: biomechanical tests and finite element analyses. J Orthop Res 2005;23(04):788-794

32 Malandrino A, Planell JA, Lacroix D. Statistical factorial analysis on the poroelastic material properties sensitivity of the lumbar intervertebral disc under compression, flexion and axial rotation. J Biomech 2009;42(16):2780-2788

33 Noailly J, Lacroix D, Planell JA. Finite element study of a novel intervertebral disc substitute. Spine 2005;30(20):2257-2264

34 Dreischarf M, Rohlmann A, Zhu R, Schmidt H, Zander T. Is it possible to estimate the compressive force in the lumbar spine from intradiscal pressure measurements? A finite element evaluation. Med Eng Phys 2013;35(09):1385-1390

35 Nachemson A. The load on lumbar disks in different positions of the body. Clin Orthop Relat Res 1966;45(45):107-122

36 Nachemson A. Lumbar intradiscal pressure. Experimental studies on post-mortem material. Acta Orthop Scand Suppl 1960; 43:1-104

37 Fagan MJ, Julian S, Mohsen AM. Finite element analysis in spine research. Proc Inst Mech Eng H 2002;216(05):281-298

38 Goto K, Tajima N, Chosa E, et al. Mechanical analysis of the lumbar vertebrae in a three-dimensional finite element method model in which intradiscal pressure in the nucleus pulposus was used to establish the model. J Orthop Sci 2002;7(02):243-246 